\title{
Geographical gradient of mean age of dengue haemorrhagic fever patients in northern Thailand
}

\author{
Y. NAGAO ${ }^{1 *}$, A. TAWATSIN ${ }^{2}$, S. THAMMAPALO ${ }^{3}$ AND U. THAVARA ${ }^{2}$ \\ ${ }^{1}$ Yao Tokushukai General Hospital, Yao, Osaka, Japan \\ ${ }^{2}$ National Institute of Health, Department of Medical Sciences, Ministry of Public Health, Nonthaburi, Thailand \\ ${ }^{3}$ Bureau of Vector Borne Disease, Department of Disease Control, Ministry of Public Health, Nonthaburi, \\ Thailand
}

(Accepted 17 March 2011; first published online 9 May 2011)

\section{SUMMARY}

Dengue haemorrhagic fever (DHF) is caused by dengue virus transmitted by Aedes mosquitoes; mean age of patients varies temporally and geographically. Variability in age of patients may be due to differences in transmission intensity or demographic structure. To compare these two hypotheses, the mean age of DHF patients from 90 districts in northern Thailand (1994-1996, 2002-2004) was regressed against (i) Aedes abundance or (ii) demographic variables (birthrate, average age) of the district. We also developed software to quantify direction and strength of geographical gradients of these variables. We found that, after adjusting for socioeconomics, climate, spatial autocorrelation, the mean age of patients was correlated only with Aedes abundance. The geographical gradient of mean age of patients originated from entomological, climate, and socioeconomic gradients. Vector abundance was a stronger determinant of mean age of patients than demographic variables, in northern Thailand.

Key words: Aedes, climate, demographic structure, Geographic Information System, socioeconomics, spatial analysis, transmission intensity, vector mosquito abundance.

\section{INTRODUCTION}

Dengue virus, which is transmitted by Aedes mosquitoes, infects more than 50 million people annually [1]. Aedes mosquitoes breed mainly in artificial water containers, such as water storage tanks, jars, and discarded tyres [2-5]. Infection with dengue virus manifests as a spectrum of illnesses, ranging from the rarely fatal dengue fever (DF) to the potentially fatal dengue haemorrhagic fever (DHF). Since DHF was first recognized in the 1950s in South East Asia, it has become a major threat to global public health, giving rise to 500000 hospitalizations annually [1].

\footnotetext{
* Author for correspondence: Dr Y. Nagao, Yao Tokushukai General Hospital, Osaka, 581-0011 Japan.

(Email: in_the_pacific214@yahoo.co.jp)
}

Interestingly, the mean age of $\mathrm{DF} / \mathrm{DHF}$ patients has been shifting in many countries [6, 7]. For example, the mean age of DF patients has steadily increased in Singapore [8, 9], and the mean age of DHF patients also increased in Thailand [10]. It was hypothesized that, at least in Singapore and Thailand, the increased mean ages of DF/DHF patients was due primarily to decreasing mosquitoes (or more generally, lower transmission intensity) as a result of successful vector control $[9,11,12]$ (Appendix 1). Indeed, it is a long-held assumption that the mean age of patients of an acute infectious disease is negatively correlated with transmission intensity [13]. However, before applying this theorem to dengue, the complex aetiology of DHF must be reviewed. Dengue virus consists of four serotypes, and most DHF cases occur 
in the presence of a pre-existing heterotypic antibody $[14,15]$; this is known as antibody-dependent enhancement. Even with this peculiar aetiology, secondary infections are most likely to occur at younger ages in areas of more intense transmission than in areas of milder transmission. Therefore, the mean age of DHF patients and transmission intensity are expected to be negatively related, even though these two variables may not be in a strictly inverse mathematical relationship. Consistent with this hypothesis, a negative relationship between an entomological index and mean age of DHF patients was reported [12].

However, the increase in the mean age of dengue illnesses in Thailand could also be explained by the changing demographic structure [16]. A larger proportion of newborns and small children in the overall population could increase the proportion of young patients; this naive population may also facilitate transmission and decrease the mean age of patients indirectly. In contrast, a higher mean age in the overall population may increase the proportion of older patients, thereby increasing the mean age of patients.

The reason for the shifting mean age of dengue illnesses is important, not only from a purely scientific viewpoint, but also from a public health standpoint, because the mean age of DHF patients could be a useful indicator for vector control if it reflects transmission intensity. The present study therefore compared mosquito abundance and demographic variables to determine their contributions to the mean age of DHF patients.

\section{METHODS}

\section{Study site and geographical data}

We obtained entomological, demographic, socioeconomic, and climate data from each of the 91 districts in northern Thailand that we had previously reported upon [17] (Fig. 1). The study site spread $580 \mathrm{~km}$ north-south by $460 \mathrm{~km}$ east-west. We used the geographical information system Mapinfo Professional (Mapinfo, USA). Digital map data was obtained from Mapinfo Thailand.

\section{Epidemiological data of DHF}

Districts in Thailand report the number of DHF cases (including dengue shock syndrome) to the Ministry of Public Health (MPH). From the MPH, we obtained the age-stratified annual number of DHF patients for
90 of the 91 districts. The remaining one district was not identified in this data, for unknown reason. From this data, the mean age of DHF cases was calculated as the midpoint of each age group (e.g. 12.5 years for the 10-14 years age group) weighted by the proportion of cases in the age group. The distribution of mean age of DHF patients was highly skewed, and hence was not suitable for linear regression analysis. Therefore, crude mean age of DHF patients (cMADHF) was transformed into normalized mean age of DHF patients (nMA-DHF), as in:

$\mathrm{nMA}-\mathrm{DHF}=\left(\mathrm{cMA}-\mathrm{DHF}^{\lambda}-1\right) / \lambda$,

where the optimal $\lambda$ was selected by the Box-Cox method [18].

\section{Entomological data}

We obtained results of two independent entomological surveys. In the first survey, community volunteers surveyed diverse villages in the 91 districts in northern Thailand in 1994, 1995 and 1996 [19]. In the second survey, public health officials surveyed the central villages of 914 districts in Thailand in April in 2002, 2003 and 2004 [12]. We used the records from northern Thailand extracted from the second survey, to be consistent with the first survey. In our analysis, the results from these two periods (1994-1996 and 2002-2004) were aggregated individually. Aedes abundance was represented by 'house index' which measures the percentage of premises positive with water containers infested with Aedes larvae/pupae. Larval indices, including house index, have limitations in their capacity to reflect the density of adult mosquitoes that determines transmission intensity most critically [20]. However, we failed to find any data representing the transmission intensity, other than house index, to cover such a wide area as our study site.

\section{Demographic data}

District-level age-stratified demographic data was obtained from the National Statistical Office (NSO) of Thailand. From this data, the average age of the district's entire population ('district average age') was estimated as the sum of the mid-point of each age group weighted by the proportion of population in this age group. The NSO data for 1995 and that for 2003 were used for the two periods, 1994-1996 and 2002-2004, respectively. The birthrate (per 1000 


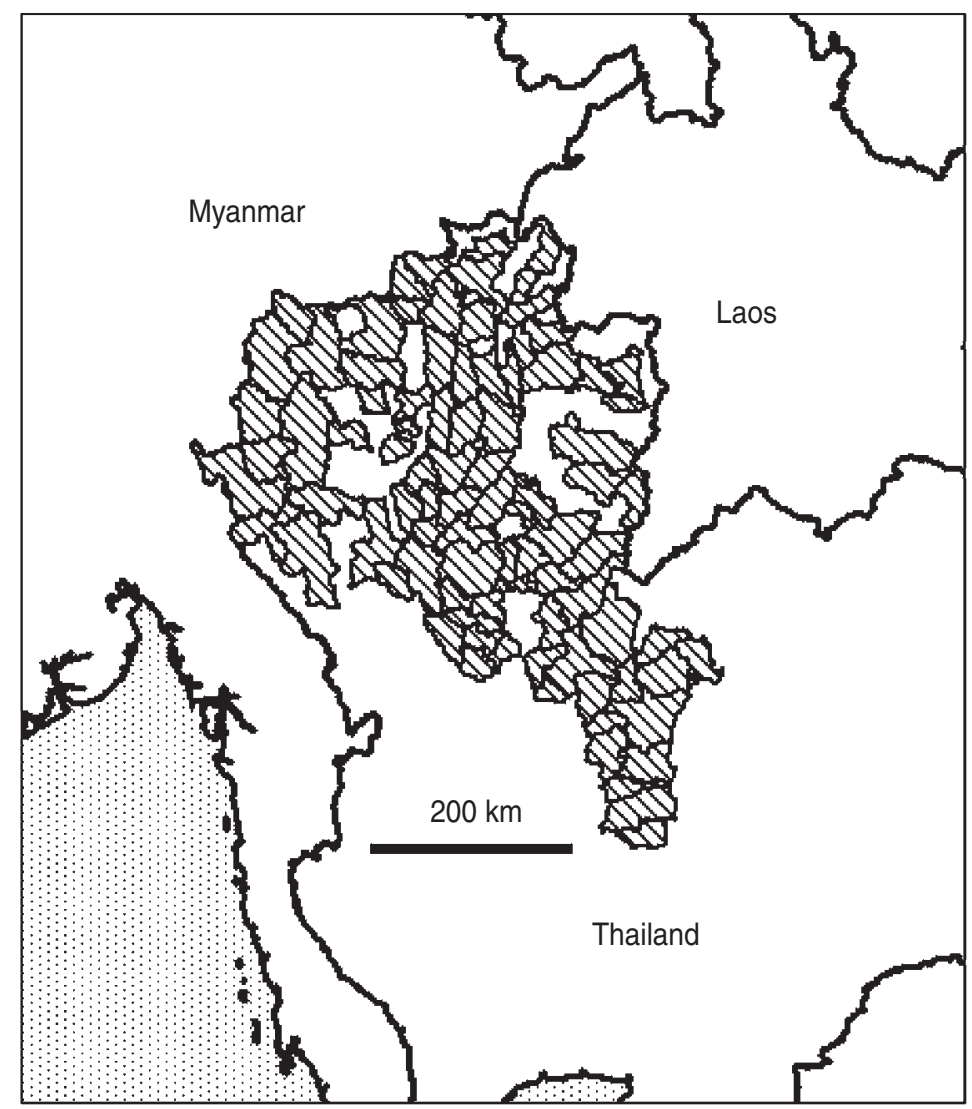

Fig. 1. Study site in northern Thailand. The 90 districts in northern Thailand studied in the present report are indicated by shading.

population) was delineated from the National Rural Database 2c (NRD2c) which was derived from biannual national census [21]. The birthrate averaged between 1994 and 1996 was used for the period of 1994-1996, while the birthrate averaged between 2002 and 2004 was used for the 2002-2004 period.

\section{Socioeconomic data}

Socioeconomic variables are known to affect dengue transmission intensity [22-24]. Our analysis which employed the NRD2c revealed that mosquito larval indices (including the house index) and the inverse of the mean age of DHF patients (which we assumed to represent transmission intensity) correlated positively with the prevalence of public large water wells, but negatively with the prevalence of private small water wells [17, 25]. These two socioeconomic variables averaged between the 1994 NRD2c and 1996 NRD2c were used for the 1994-1996 period, while those averaged between the 2002 NRD2c and 2004 NRD2c were used for the 2002-2004 period.

\section{Climate data}

Climate exerts a complex effect on dengue transmission intensity. High temperature increases transmission intensity by enhancing mosquito survival [26] and hastening viral incubation in mosquitoes [27]. However, extremely high temperature increases the mortality of mosquito eggs [28], and adult mosquitoes [29]. Similarly, aridity decreases mosquito longevity [30], but may increase the need for household water containers and consequently the number of breeding sites. Previously, we reported that average pan evapotranspiration (APET), which measures the water that evaporates from a standardized pan [31], predicts the mean age of DHF cases better than any other single climatic variable in Thailand [25]. Furthermore, evapotranspiration quantifies aridity by taking into account numerous climatic variables: solar radiation, temperature, humidity, and wind speed [32, 33]. Therefore, our present analysis used only APET to represent climatic conditions relevant to the mean age of DHF patients. Monthly APET values at 89 weather stations in Indochina were obtained from the 
Table 1. Attributes of 90 districts in northern Thailand

\begin{tabular}{|c|c|c|}
\hline & 1994-1996 Mean (range) & 2002-2004 Mean (range) \\
\hline \multicolumn{3}{|l|}{ 1. Epidemiological data of DHF } \\
\hline Incidence (per 100000 population) & $68 \cdot 5(4 \cdot 10-309)$ & $42 \cdot 6(0 \cdot 647-181)$ \\
\hline Mean age of patients (years) & $15 \cdot 0(7 \cdot 50-33 \cdot 3)$ & $19 \cdot 0(7 \cdot 50-50 \cdot 0)$ \\
\hline \multicolumn{3}{|l|}{ 2. Entomological data } \\
\hline House index $(\%)$ & $36 \cdot 7(1 \cdot 82-94 \cdot 7)$ & $15 \cdot 2(1 \cdot 18-49 \cdot 0)$ \\
\hline \multicolumn{3}{|l|}{ 3. Demographic data } \\
\hline District average age (years) & $31 \cdot 3(26 \cdot 5-34 \cdot 9)$ & $33 \cdot 9(27 \cdot 7-37 \cdot 5)$ \\
\hline Birthrate per 1000 population & $13 \cdot 9(7 \cdot 94-26 \cdot 3)$ & $8 \cdot 93(1 \cdot 30-63 \cdot 9)$ \\
\hline \multicolumn{3}{|l|}{ 4. Socioeconomic data } \\
\hline Public large wells (per capita) & $0 \cdot 00300(0 \cdot 000327-0 \cdot 0153)$ & $0 \cdot 00421(0-0 \cdot 0112)$ \\
\hline Private small wells (per capita) & $0 \cdot 0521(0 \cdot 000561-0 \cdot 183)$ & $0 \cdot 0620(0 \cdot 000435-0 \cdot 174)$ \\
\hline \multicolumn{3}{|l|}{ 5. Climatic data } \\
\hline APET (mm/day) & $3 \cdot 65(3 \cdot 54-3 \cdot 78)$ & $3 \cdot 80(3 \cdot 67-3 \cdot 95)$ \\
\hline
\end{tabular}

APET, Average pan evapotranspiration; DHF, dengue haemorrhagic fever.

University Corporation for Atmospheric Research [34], averaged through the two periods individually, and interpolated to the geographical centre of each district using inverse distance weighting [25].

\section{Identification of geographical gradient of district attribute variables}

We created a density (thematic) map for each district attribute variable. To interpret the pattern in each density map objectively, we developed a methodology to quantify the direction and strength of geographical gradients of the district attributes (Appendix 2).

\section{Statistical analysis}

The relationships between normalized mean age of DHF patients and entomological or demographic variables at the district level were evaluated by conventional linear regression analysis. The effects of socioeconomic/climatic covariates were adjusted in multivariate analyses. We controlled for possible biases deriving from spatial autocorrelation (i.e. districts near each other tend to exhibit similar values), by using the following spatial regression analysis [35]:

$$
\boldsymbol{Y}=\rho \boldsymbol{W} \boldsymbol{Y}+\boldsymbol{X} \boldsymbol{\beta}+\mu,
$$

where $\boldsymbol{X}$ and $\boldsymbol{Y}$ denote independent and dependent variables, respectively, $\boldsymbol{\beta}$ denotes the regression coefficient vector, $\rho$ denotes the spatial autoregressive parameter, and $\boldsymbol{W}$ represents the row-standardized spatial neighbourhood matrix. Each element of the spatial neighbourhood matrix is assigned the value ' 1 ' if the given pair of district centres are within a predefined distance ('neighbourhood distance'), and ' 0 ' otherwise. As a result, $\boldsymbol{W} \boldsymbol{Y}$ expresses a spatially lagged dependent variable. Stata v. 9.0 (Stata Corporation, USA) was used for statistical analyses. Software for the spatial regression analysis was provided by Maurizio Pisati. The data and software prepared for the present study are available from our website (see Appendix 3).

\section{RESULTS}

\section{Geographical gradient of district attributes}

The data used in our analysis are summarized in Table 1. The attributes examined in our analysis varied from district to district greatly, as shown in Table 1. A total of 13388 cases of DHF were reported during the 1994-1996 period, while 10179 cases were reported between 2002 and 2004. The mean and range of house index were very different between the two periods. This may reflect the fact that more heterogeneous villages were surveyed in the 1994-1996 survey than in the 2002-2004 survey, the latter of which investigated only the district centres, and only in April.

The incidence of DHF (magnitude and distribution) varied from year to year (Fig. 2). In contrast, the mean age of DHF patients was consistently higher in the northwestern districts throughout the two study periods (Fig. 3), whereas the vector abundance was consistently higher in the southeastern districts (Fig. 4). The spatial trends of district average age and birthrate were not remarkable (Fig. $5 a, b$ ). Public large wells were common in the southeastern districts (Fig. 5c), whereas private small wells were more 
(a) 1994

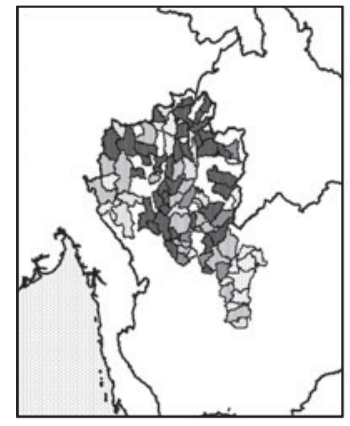

(d) 2002

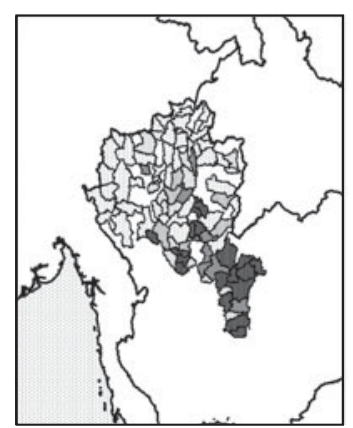

(b) 1995

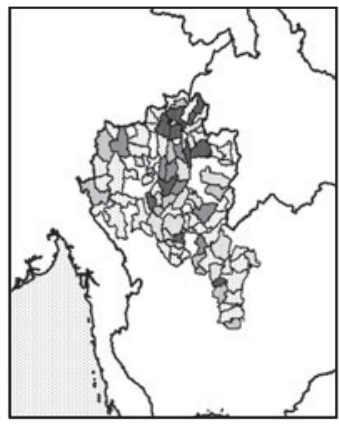

(e) 2003

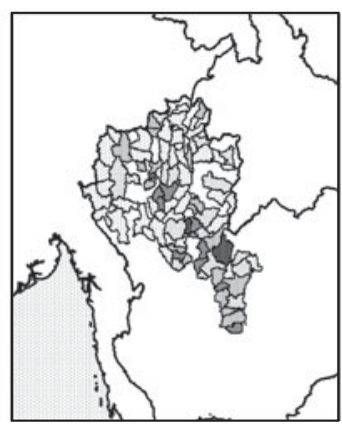

(c) 1996

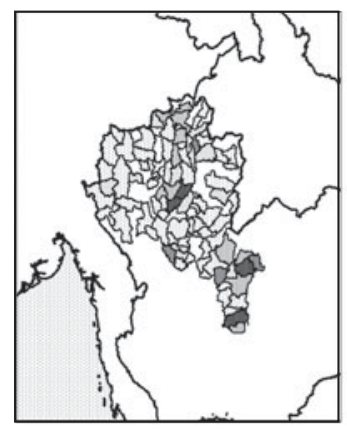

(f) 2004

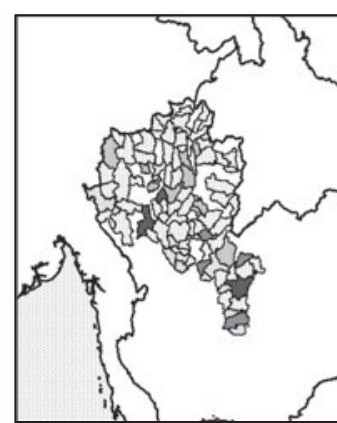

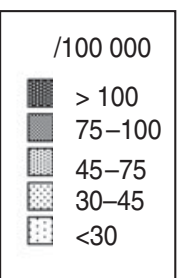

Fig. 2. Spatial and temporal heterogeneity in incidence of dengue haemorrhagic fever (DHF). The annual incidence of DHF was estimated for each of 90 districts in northern Thailand.

common in the northern districts (Fig. 5d); APET was high in southeastern districts (Fig. 5e). These observations were confirmed by spatial gradient analysis (Fig. 6). In both periods, APET, public large wells, and house index showed statistically significant gradients to the southeast, whereas mean age of DHF patients exhibited gradients in the opposite direction.

\section{Normalization of mean age of DHF patients}

The variable crude mean age of DHF patients was transformed into normalized mean age of DHF patients by applying equation (1) $(\lambda=-0.499$ for 1994-1996; $\lambda=-0 \cdot 157$ for 2002-2004). This transformation does not affect the rank (see Supplementary Fig. 1, available online).

\section{Conventional regression analysis}

Table 2 presents the result of conventional (i.e. nonspatial) univariate regression analysis. It was shown that normalized mean age of DHF patients was correlated with house index in both periods (1994-1996: $\left.R^{2}=33, P<0 \cdot 001 ; 2002-2004: R^{2}=0 \cdot 22, P<0 \cdot 001\right)$, and more weakly with district average age only in the 1994-1996 period $\left(R^{2}=0.097, P=0.003\right)$; however, normalized mean age of DHF patients was not correlated significantly with district average age in the 2002-2004 period $(P=0 \cdot 297)$, or with birthrate in either period (1994-1996: $P=0 \cdot 692 ; 2002-2004$ : $P=0 \cdot 183$ ) (see also Supplementary Fig. 2, online).

As shown in Table 3, conventional multivariate analysis revealed that the normalized mean age of DHF patients was correlated significantly with house index in both periods (1994-1996: $P=0.002$; 2002-2004: $P=0.038$ ). However, in either period, normalized mean age of patients was not correlated with birthrate (1994-1996: $P=0 \cdot 214 ; 2002-2004: P=$ $0 \cdot 432)$ or district average age (1994-1996: $P=0.877$; 2002-2004: $P=0 \cdot 346)$.

\section{Spatial regression analysis}

The largest minimum distance between districts was $54 \mathrm{~km}$, while the smallest maximum distance was $287 \mathrm{~km}$. Therefore, we defined the neighbourhood distance as $100 \mathrm{~km}$. Spatial univariate regression analysis showed that, in both periods, normalized mean age of DHF patients was significantly correlated 
(a) 1994

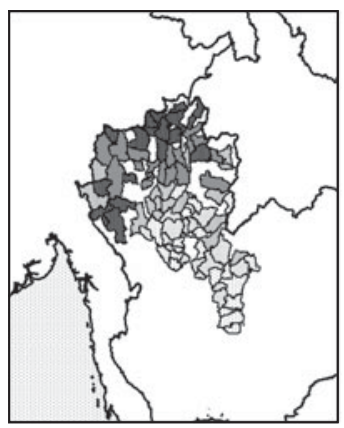

(d) 2002

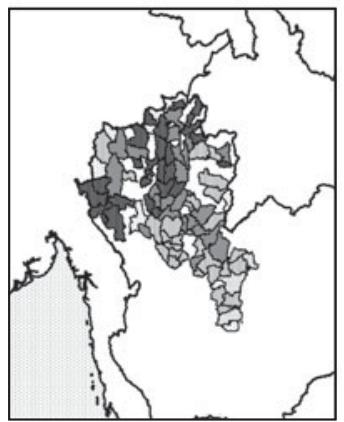

(b) 1995

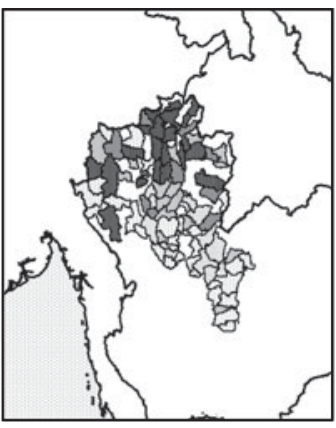

(e) 2003

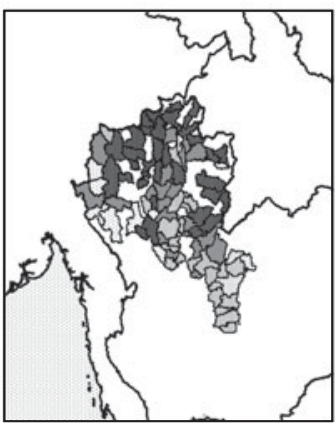

(c) 1996

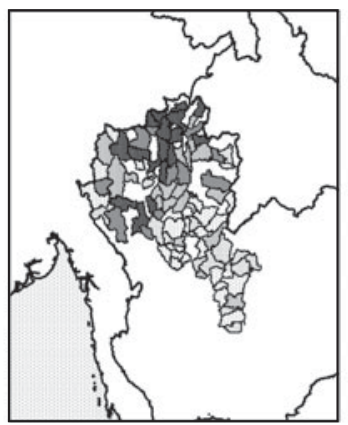

(f) 2004

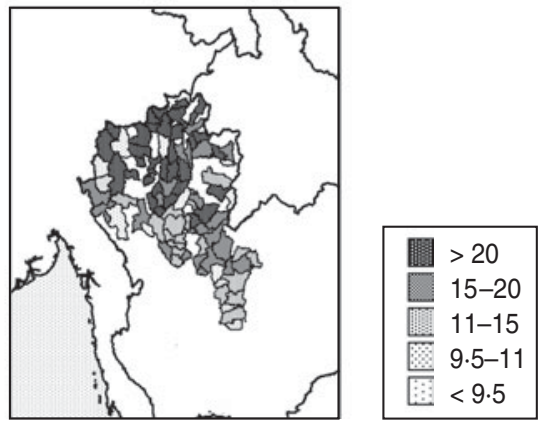

Fig. 3. Spatial and temporal heterogeneity in mean age of patients with dengue haemorrhagic fever (DHF). The mean age of DHF patients reported was estimated for each of 90 districts in northern Thailand.

(a) 1994

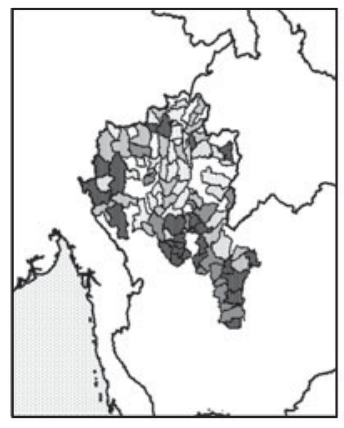

(d) 2002

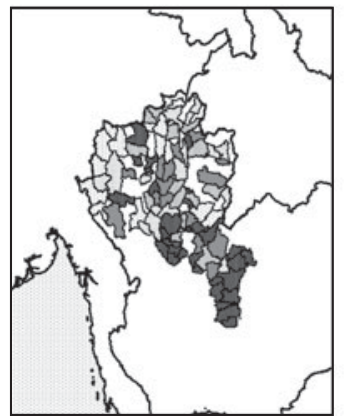

(b) 1995

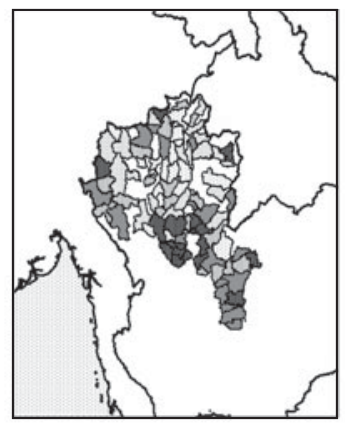

(e) 2003

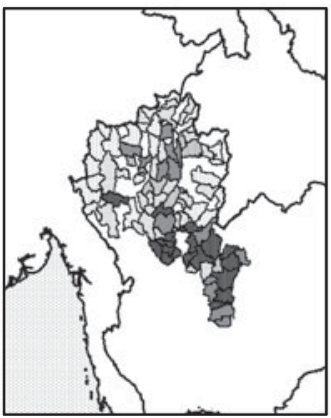

(c) 1996

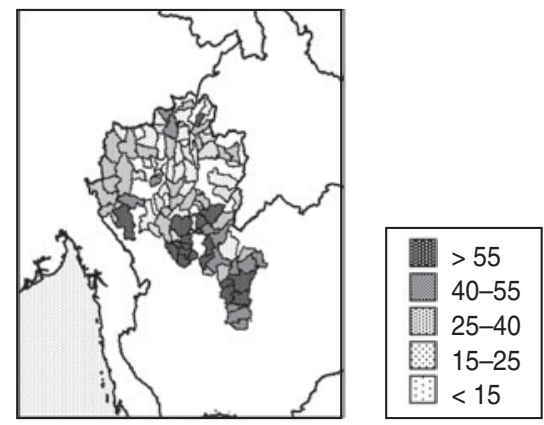

(f) 2004

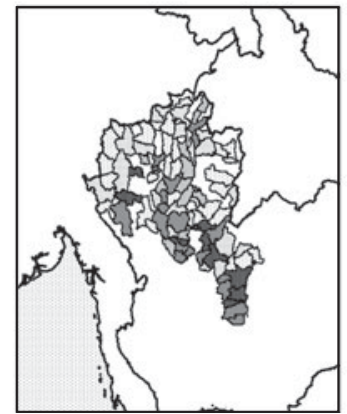

$>22.5$

15-22.5

12.5-15

$7 \cdot 5-12.5$

$<7.5$

Fig. 4. Spatial and temporal heterogeneity in vector mosquito abundance. The house index (i.e. percentage of premises positive with water containers infested with Aedes larvae/pupae) was averaged at the district level. Since the survey conducted between 1994 and 1996 and the survey conducted between 2002 and 2004 were based upon different schemes, keys are presented for the individual periods. 
(a) District average age

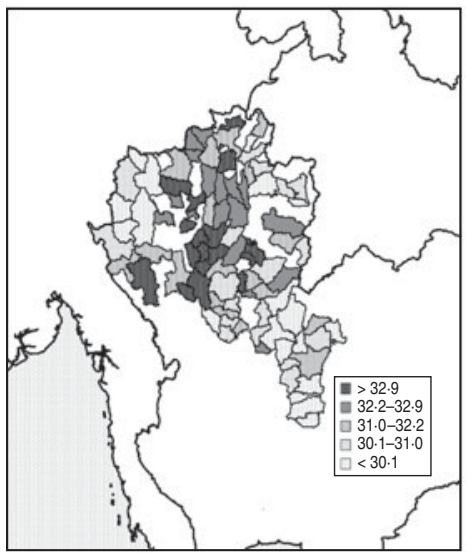

(d) Private small wells

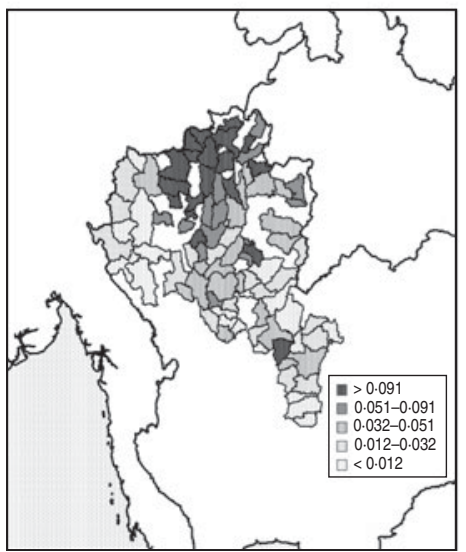

(b) Birthrate

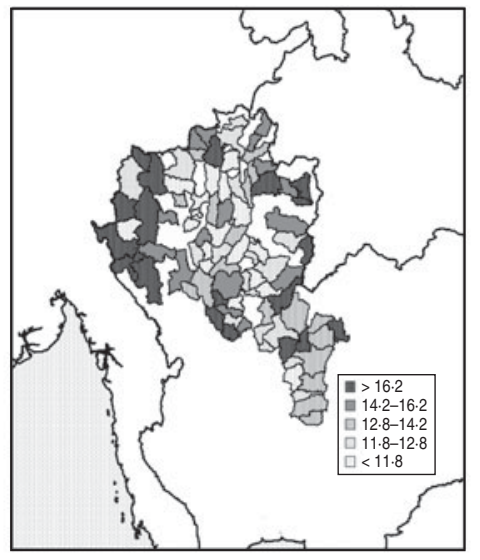

(e) APET

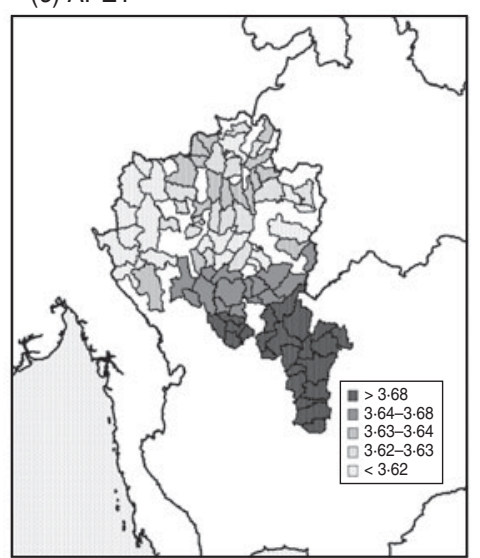

(c) Public large wells

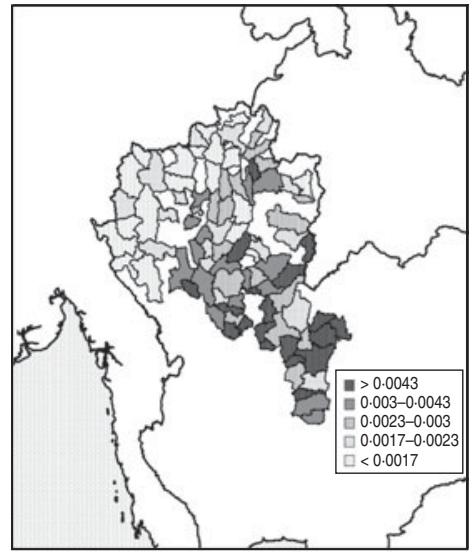

Fig. 5. Spatial heterogeneity in demographic, socioeconomic and climatic variables. (a) Average age of the entire population of each district ('district average age'), (b) birthrate (in a population of 1000), (c) per capita number of public large wells, (d) per capita number of private small wells, and (e) average pan evapotranspiration (APET, $\mathrm{mm} /$ day) representing aridity are shown for the 1994-1996 period. The spatial trend of each variable was largely similar in the 2002-2004 period.

(a) 1994-1996

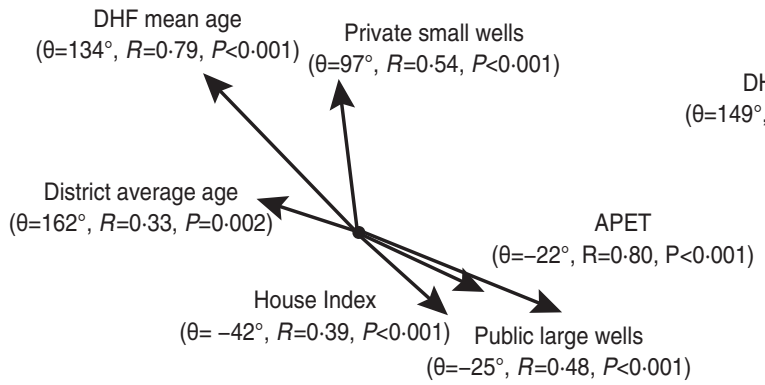

(b) 2002-2004

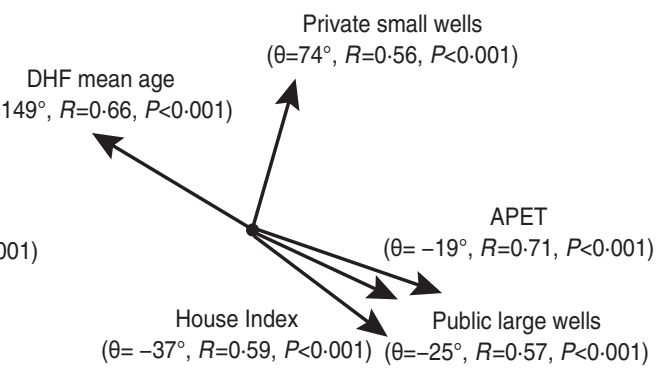

Fig. 6. Geographical gradient of district attributes. The geographical gradients of the district-level attribute variables were estimated using the method described in Appendix 2. The gradient direction $(\theta)$, the strength of gradient $(R)$, and its statistical significance $(P)$ are presented in parentheses. The length of each arrow represents $R$. Variables which did not show significant gradients were omitted (i.e. birthrate in both periods; district average age in the 2002-2004 period).

with house index (1994-1996: $P<0 \cdot 001: 2002-2004$ : $P=0.029)$, but not with birthrate (1994-1996: $P=0.515 ; 2002-2004: P=0 \cdot 362)$ or district average age (1994-1996: $P=0 \cdot 272 ; 2002-2004: P=0 \cdot 947)$ (Table 4). Spatial multivariate regression analysis supported these results (Table 5). During the 
Table 2. Conventional univariate regression analysis to explain normalized mean age of dengue haemorrhagic fever patients

\begin{tabular}{|c|c|c|c|c|c|c|c|c|}
\hline Variable & Coeff. & $P$ & Variable & Coeff. & $P$ & Variable & Coeff. & $P$ \\
\hline \multicolumn{9}{|l|}{ 1994-1996 } \\
\hline House index & $-0 \cdot 0027$ & $<0.001$ & Birthrate & $0 \cdot 0015$ & 0.692 & District average age & $0 \cdot 017$ & $0 \cdot 003$ \\
\hline Constant & $1 \cdot 6$ & & Constant & $1 \cdot 4$ & & Constant & $0 \cdot 92$ & \\
\hline$R^{2}$ & $0 \cdot 33$ & & $R^{2}$ & $0 \cdot 0018$ & & $R^{2}$ & $0 \cdot 097$ & \\
\hline \multicolumn{9}{|l|}{ 2002-2004 } \\
\hline House index & $-0 \cdot 011$ & $<0 \cdot 001$ & Birthrate & $-0 \cdot 0035$ & $0 \cdot 183$ & District average age & $0 \cdot 011$ & $0 \cdot 297$ \\
\hline Constant & $2 \cdot 5$ & & Constant & $2 \cdot 3$ & & Constant & $2 \cdot 0$ & \\
\hline$R^{2}$ & $0 \cdot 22$ & & $R^{2}$ & $0 \cdot 020$ & & $R^{2}$ & $0 \cdot 012$ & \\
\hline
\end{tabular}

Coeff., Coefficient.

Table 3. Conventional multivariate regression analysis to explain normalized mean age of dengue haemorrhagic fever patients

\begin{tabular}{|c|c|c|c|c|c|c|c|c|}
\hline Variable & Coeff. & $P$ & Variable & Coeff. & $P$ & Variable & Coeff. & $P$ \\
\hline \multicolumn{9}{|l|}{ 1994-1996 } \\
\hline House index & $-0 \cdot 0013$ & $0 \cdot 002$ & Birthrate & $0 \cdot 0034$ & $0 \cdot 214$ & District average age & -0.00076 & $0 \cdot 877$ \\
\hline Public large wells & -11 & 0.009 & Public large wells & -10 & 0.023 & Public large wells & -11 & $0 \cdot 016$ \\
\hline Private small wells & $0 \cdot 61$ & $0 \cdot 001$ & Private small wells & $0 \cdot 83$ & $<0.001$ & Private small wells & $0 \cdot 77$ & $<0.001$ \\
\hline APET & $-0 \cdot 72$ & $<0 \cdot 001$ & APET & $-0 \cdot 95$ & $<0.001$ & APET & -0.97 & $<0.001$ \\
\hline Constant & $4 \cdot 1$ & & Constant & $4 \cdot 9$ & & Constant & $5 \cdot 0$ & \\
\hline$R^{2}$ & $0 \cdot 59$ & & $R^{2}$ & $0 \cdot 54$ & & $R^{2}$ & $0 \cdot 54$ & \\
\hline \multicolumn{9}{|l|}{ 2002-2004 } \\
\hline House index & $-0 \cdot 0047$ & $0 \cdot 038$ & Birthrate & $-0 \cdot 0017$ & $0 \cdot 432$ & District average age & $-0 \cdot 0088$ & $0 \cdot 346$ \\
\hline Public large wells & -22 & $0 \cdot 029$ & Public large wells & -25 & $0 \cdot 019$ & Public large wells & -20 & $0 \cdot 071$ \\
\hline Private small wells & $1 \cdot 3$ & $0 \cdot 001$ & Private small wells & $1 \cdot 3$ & $0 \cdot 001$ & Private small wells & $1 \cdot 6$ & $<0.001$ \\
\hline APET & $-0 \cdot 62$ & $0 \cdot 100$ & APET & $-0 \cdot 94$ & 0.007 & APET & $-1 \cdot 1$ & $0 \cdot 004$ \\
\hline Constant & $4 \cdot 7$ & & Constant & $5 \cdot 9$ & & Constant & $6 \cdot 6$ & \\
\hline$R^{2}$ & $0 \cdot 44$ & & $R^{2}$ & $0 \cdot 42$ & & $R^{2}$ & $0 \cdot 42$ & \\
\hline
\end{tabular}

Coeff., Coefficient; APET, average pan evapotranspiration (mm/day).

Table 4. Spatial univariate regression analysis to explain normalized mean age of dengue haemorrhagic fever patients

\begin{tabular}{|c|c|c|c|c|c|c|c|c|}
\hline Variable & Coeff. & $P$ & Variable & Coeff. & $P$ & Variable & Coeff. & $P$ \\
\hline \multicolumn{9}{|l|}{ 1994-1996 } \\
\hline House index & $-0 \cdot 0010$ & $<0 \cdot 001$ & Birthrate & $0 \cdot 0013$ & $0 \cdot 515$ & District average age & $0 \cdot 0036$ & $0 \cdot 272$ \\
\hline Constant & $0 \cdot 27$ & & Constant & $0 \cdot 096$ & & Constant & $0 \cdot 022$ & \\
\hline$\rho$ & $0 \cdot 84$ & & $\rho$ & $0 \cdot 92$ & & $\rho$ & $0 \cdot 91$ & \\
\hline$R^{2}$ & $0 \cdot 74$ & & $R^{2}$ & $0 \cdot 72$ & & $R^{2}$ & $0 \cdot 72$ & \\
\hline \multicolumn{9}{|l|}{ 2002-2004 } \\
\hline House index & $-0 \cdot 0044$ & 0.029 & Birthrate & $-0 \cdot 0018$ & $0 \cdot 362$ & District average age & $0 \cdot 00050$ & 0.947 \\
\hline Constant & $0 \cdot 70$ & & Constant & $0 \cdot 45$ & & Constant & $0 \cdot 40$ & \\
\hline$\rho$ & $0 \cdot 73$ & & $\rho$ & $0 \cdot 81$ & & $\rho$ & $0 \cdot 82$ & \\
\hline$R^{2}$ & $0 \cdot 47$ & & $R^{2}$ & $0 \cdot 47$ & & $R^{2}$ & $0 \cdot 47$ & \\
\hline
\end{tabular}

Coeff., Coefficient. 
Table 5. Spatial multivariate regression analysis to explain normalized mean age of dengue haemorrhagic fever patients

\begin{tabular}{|c|c|c|c|c|c|c|c|c|}
\hline Variable & Coeff. & $P$ & Variable & Coeff. & $P$ & Variable & Coeff. & $P$ \\
\hline \multicolumn{9}{|l|}{ 1994-1996 } \\
\hline House index & $-0 \cdot 0010$ & $<0 \cdot 001$ & Birthrate & $0 \cdot 0014$ & $0 \cdot 491$ & District average age & $0 \cdot 0036$ & $0 \cdot 332$ \\
\hline Public large wells & $-6 \cdot 4$ & 0.039 & Public large wells & $-6 \cdot 2$ & $0 \cdot 067$ & Public large wells & $-7 \cdot 2$ & $0 \cdot 033$ \\
\hline Private small wells & $0 \cdot 028$ & $0 \cdot 856$ & Private small wells & $0 \cdot 18$ & $0 \cdot 279$ & Private small wells & $0 \cdot 076$ & $0 \cdot 661$ \\
\hline APET & $0 \cdot 15$ & $0 \cdot 391$ & APET & $-0 \cdot 048$ & $0 \cdot 784$ & APET & $0 \cdot 020$ & $0 \cdot 913$ \\
\hline Constant & $-0 \cdot 24$ & & Constant & $0 \cdot 42$ & & Constant & $0 \cdot 051$ & \\
\hline$\rho$ & $0 \cdot 83$ & & $\rho$ & $0 \cdot 83$ & & $\rho$ & $0 \cdot 85$ & \\
\hline$R^{2}$ & 0.75 & & $R^{2}$ & $0 \cdot 72$ & & $R^{2}$ & $0 \cdot 72$ & \\
\hline \multicolumn{9}{|l|}{ 2002-2004 } \\
\hline House index & -0.0036 & $0 \cdot 090$ & Birthrate & -0.0017 & 0.379 & District average age & -0.0040 & $0 \cdot 646$ \\
\hline Public large wells & -18 & $0 \cdot 048$ & Public large wells & -20 & 0.032 & Public large wells & -17 & $0 \cdot 081$ \\
\hline Private small wells & $0 \cdot 70$ & 0.077 & Private small wells & $0 \cdot 62$ & $0 \cdot 133$ & Private small wells & 0.80 & $0 \cdot 075$ \\
\hline APET & $-0 \cdot 083$ & $0 \cdot 831$ & APET & $-0 \cdot 26$ & & APET & $-0 \cdot 34$ & $0 \cdot 382$ \\
\hline Constant & 1.6 & & Constant & $2 \cdot 1$ & & Constant & $2 \cdot 6$ & \\
\hline$\rho$ & $0 \cdot 50$ & & $\rho$ & $0 \cdot 55$ & & $\rho$ & $0 \cdot 53$ & \\
\hline$R^{2}$ & $0 \cdot 50$ & & $R^{2}$ & $0 \cdot 49$ & & $R^{2}$ & $0 \cdot 49$ & \\
\hline
\end{tabular}

Coeff., Coefficient; APET, average pan evapotranspiration (mm/day).

1994-1996 period, normalized mean age of DHF patients was correlated significantly with house index $(P<0.001)$ but not with birthrate $(P=0 \cdot 491)$ or district average age $(P=0 \cdot 332)$. During the 2002-2004 period, normalized mean age of patients showed a marginally significant correlation with house index $(P=0 \cdot 090)$, although correlations with birthrate and district average age were clearly non-significant ( $P=0.379$ and $P=0.646$, respectively). Repeating these analyses with an alternative neighbourhood distance of $200 \mathrm{~km}$ did not affect the results qualitatively (see 'Log of statistical analyses' in Appendix 3).

\section{DISCUSSION}

The mean age of patients of dengue illnesses has shifted in many countries. Two apparently opposing hypotheses have been proposed as the mechanism underlying this phenomenon, i.e. mosquito abundance [11] vs. demographic structure [16]. However, to our knowledge, no study has compared the contribution of these two factors to the age of dengue patients, using entomological and demographic data. By using actual entomological/demographic data, the present study demonstrated that the mean age of DHF patients was correlated with mosquito abundance, but not with the demographic variables evaluated, after controlling for potential confounders (socioeconomics, climate, or spatial autocorrelation).
Thus, mosquito abundance appears to exert more influence on the mean age of DHF patients than demographic factors, in our study site and period.

Shift in age-dependent exposure to mosquitoes also has been proposed as an explanation for the change in the mean age of dengue patients [36]. A decrease in the exposure in infants and younger children, for example due to the widespread use of air conditioners in households, would most likely increase the age of infections, thereby raising the mean age of patients. This explanation should be tested in epidemiological studies.

Identification of spatial and/or temporal clusters of dengue would assist not only understanding of disease dynamics but disease control programmes [37-39]. However, our study site was irregularly shaped and contained gaps (Fig. 1), which hindered such analyses. Alternatively, we focused upon geographical gradient. A limited number of dengue/Aedes studies have paid attention to geographical gradient [40,41], which has been a frequent topic in ecological and public health studies [42, 43]. However, almost all of the previous studies used only east-west or north-south directions. By examining all directions, the present study revealed that the geographical gradient of mosquito abundance showed a similarity to that of public large wells, but was in opposite direction to the gradient of private small wells. We hypothesize that use of public water wells requires water storage in 
individual households, which would increase Aedes abundance, whereas use of private wells would decrease the need for household water storage. Interestingly, the geographical gradient of aridity (i.e. APET) was correlated positively with public large wells, but negatively with private small wells. These correlations between mode of water use and climate may be explained as follows. Because underground water is located in deep aquifers in arid regions, large wells are needed. Digging such large-scale water wells requires considerable investment, which accounts for the high number of public wells in arid districts (Fig. 5). Consequently, Aedes abundance is affected by the mode of water use, the latter of which is determined by climate. An alternative (but not mutually exclusive) explanation for the positive relationship between aridity and Aedes is that dry conditions necessitate storing rainwater in individual households [44].

Taken together, our results show that the mean age of DHF patients is associated with vector mosquito abundance rather than demographic factors. In the present study, the spatial spread was limited. In particular, our study site did not include Bangkok that was reported to be the epicentre of dynamic spread of dengue [45]. In addition, the second entomological survey, which surveyed only the district centres, did not capture the heterogeneity in the districts completely (Table 1). This reduced sensitivity of the second entomological survey may account for the marginally significant correlation in the spatial multivariate regression (Table 5). Therefore, similar studies should be conducted in a wider area, including Bangkok, surveying both urban and rural areas. However, the results of the present study suggest that the mean age of DHF patients may be an indicator of transmission intensity in endemic countries.

\section{APPENDIX 1}

\section{Negative relationship between mean age of DHF patients and dengue transmission intensity}

Transmission intensity can be represented by the basic reproduction number $R_{0}$, i.e. the number of new infections originating from one infectious individual in a susceptible population. $R_{0}$ is considered to be proportionate to the vector abundance [46]. There have been numerous attempts to estimate $R_{0}$ [47-49]. We proposed expressing $R_{0}$ in a stable endemic state as a function of the mean age of DHF patients $\left(A_{\mathrm{DHF}}\right)$ according to the following equation [11]:

$$
\begin{aligned}
R_{0}= & \frac{H}{A_{\mathrm{DHF}}}\left[\left(\frac{p_{1}}{\sum_{i} p_{i}} \times \frac{1}{4}\right)+\left(\frac{p_{2}}{\sum_{i} p_{i}} \times\left(\frac{1}{4}+\frac{1}{3}\right)\right)\right. \\
& +\left(\frac{p_{3}}{\sum_{i} p_{i}} \times\left(\frac{1}{4}+\frac{1}{3}+\frac{1}{2}\right)\right) \\
& \left.+\left(\frac{p_{4}}{\sum_{i} p_{i}} \times\left(\frac{1}{4}+\frac{1}{3}+\frac{1}{2}+1\right)\right)\right],
\end{aligned}
$$

where $H$ denotes host life expectancy, and $p_{i}$ denotes the probability of DHF developing in the $i$ th infection. By incorporating realistic parameters $(H=70$ years, $\left.p_{1}=0.002, p_{2}=p_{3}=p_{4}=0.04\right)$ based upon an epidemiological study [50], equation (3) can be simplified as:

$R_{\mathbf{0}}=87 / A_{\mathrm{DHF}}$.

This relationship is depicted as open circles in Supplementary Figure 3 (online). An individualbased model was built with the same parameters [12]; the relationship between $A_{\mathrm{DHF}}$ and $R_{0}$ using this simulation is depicted as the closed circles in Supplementary Figure 3 (online). The similarity between $A_{\mathrm{DHF}}-R_{0}$ relationships predicted by these different methods supports our assumption that $A_{\mathrm{DHF}}$ can be used as a reverse indicator of $R_{\mathbf{0}}$, at least in terms of rank.

\section{APPENDIX 2}

\section{Identification of the spatial gradient of an attribute variable}

We developed a methodology to identify the spatial gradients of district-level attribute variables. The location of the each district was expressed as $(\mathrm{x}, \mathrm{y})$ on the Universal Transverse Mercator (UTM) coordinate system, where $\mathrm{x}$ and $\mathrm{y}$ are longitude and latitude, respectively (see Supplementary Fig. 4, online). To search for the gradient direction of an attribute variable $\boldsymbol{A}$, an axis was rotated which intersects the $\mathrm{x}$ axis of UTM with an angle of $\theta$. The $(\mathrm{x}, \mathrm{y})$ was projected to this rotating axis. As a result, the coordinate of the district on this rotating axis $(\boldsymbol{L})$ can be expressed by $\mathrm{x}$, $\mathrm{y}$, and $\theta$ as:

$$
\left.\begin{array}{rl}
L & =\sqrt{\left(x^{2}+y^{2}\right)} \times \cos (\delta-\theta) \\
& =\sqrt{\left(x^{2}+y^{2}\right)} \times \cos (\arctan (\mathrm{y} / \mathrm{x})-\theta) .
\end{array}\right\}
$$


While $\theta$ was increased incrementally from $-\pi$ $\left(-180^{\circ}\right)$ to $+\pi\left(180^{\circ}\right)$, the correlation coefficient $(R)$ between $\boldsymbol{A}$ and $\boldsymbol{L}$ was recorded for each $\theta$. The $\theta$ that generated the largest $R$ (i.e. strongest correlation) was assumed to be the gradient of the variable $A$, whereas $R$ represented the gradient strength.

\section{APPENDIX 3}

\section{Data files available from our website}

The following data files used in the present study are available at: http://www.geocities.jp/vector_borne_ diseases/gradient/gradient_of_dhf.html.

Attributes of each of the 90 districts (amphoes).

Age-stratified number of DHF patients reported from the 90 districts of northern Thailand.

Log of statistical analyses.

Software code developed for the geographical gradient analysis.

Input data for the gradient analysis.

Output data files from the gradient analysis.

\section{NOTE}

Supplementary material accompanies this paper on the Journal's website (http://journals.cambridge.org/ hyg).

\section{ACKNOWLEDGEMENTS}

We are grateful to Maurizio Pisati for proving spatial analysis software, and to Pongsvas Svasti for his assistance in the analysis of the NRD2c database.

\section{DECLARATION OF INTEREST}

None.

\section{REFERENCES}

1. World Health Organization (http://www.who.int/ mediacentre/factsheets/fs117/en/). Accessed 2010.

2. Lambdin BH, et al. Dry season production of filariasis and dengue vectors in American Samoa and comparison with wet season production. American Journal of Tropical Medicine and Hygiene 2009; 81 : 1013-1019.

3. Higa Y, et al. Geographic distribution of Aedes aegypti and Aedes albopictus collected from used tires in Vietnam. Journal of the American Mosquito Control Association 2010; 26: 1-9.

4. Koenraadt CJ, et al. Spatial and temporal patterns in pupal and adult production of the dengue vector Aedes aegypti in Kamphaeng Phet, Thailand. American Journal of Tropical Medicine and Hygiene 2008; 79: 230-238.

5. Nathan MB, Knudsen AB. Aedes aegypti infestation characteristics in several Caribbean countries and implications for integrated community-based control. Journal of the American Mosquito Control Association $1991 ; 7: 400-404$.

6. Guha-Sapir D, Schimmer B. Dengue fever: new paradigms for a changing epidemiology. Emerging Themes in Epidemiology 2005; 2: 1.

7. Teixeira MG, et al. Recent shift in age pattern of dengue hemorrhagic fever, Brazil. Emerging Infectious Diseases 2008; 14: 1663.

8. Ooi EE, Goh KT, Chee Wang DN. Effect of increasing age on the trend of dengue and dengue hemorrhagic fever in Singapore. International Journal of Infectious Diseases 2003; 7: 231-232.

9. Egger JR, et al. Reconstructing historical changes in the force of infection of dengue fever in Singapore: implications for surveillance and control. Bulletin of the World Health Organization 2008; 86: 187-196.

10. Chareonsook O, et al. Changing epidemiology of dengue hemorrhagic fever in Thailand. Epidemiology and Infection 1999; 122: 161-166.

11. Nagao Y, Koelle K. Decreases in dengue transmission may act to increase the incidence of dengue hemorrhagic fever. Proceedings of the National Academy of Sciences USA 2008; 105: 2238-2243.

12. Thammapalo $\mathbf{S}$, et al. Relationship between transmission intensity and incidence of dengue hemorrhagic fever in Thailand. PLoS Neglected Tropical Diseases 2008; 2: e263.

13. Anderson RM, May RM. Infectious Diseases of Humans: Dynamics and Control. Oxford: Oxford University Press, 1991.

14. Hawkes RA. Enhancement of the infectivity of arboviruses by specific antisera produced in domestic fowls. Australian Journal of Experimental Biology and Medical Science $1964 ;$ 42: 465-482.

15. Halstead SB, Nimmannitya S, Cohen SN. Observations related to pathogenesis of dengue hemorrhagic fever. IV. Relation of disease severity to antibody response and virus recovered. Yale Journal of Biology and Medicine $1970 ;$ 42: 311-328.

16. Cummings DA, et al. The impact of the demographic transition on dengue in Thailand: insights from a statistical analysis and mathematical modeling. PLoS Medicine 2009; 6: e1000139.

17. Nagao Y, et al. Climatic and social risk factors for Aedes infestation in rural Thailand. Tropical Medicine and International Health 2003; 8: 650-659.

18. Box GEP, Cox DR. An analysis of transformations. Journal of the Royal Statistical Society, Series B 1964; 26: 211-243.

19. Suwonkerd W, Prachakwong S. The Entomological Surveillance for Dengue Hemorrhagic Fever in 13 Provinces in Northern Thailand. Chiang Mai: The Future Print Publisher, 1996. 
20. Focks DA, Chadee DD. Pupal survey: an epidemiologically significant surveillance method for Aedes aegypti: an example using data from Trinidad. American Journal of Tropical Medicine and Hygiene 1997; 56: 159-167.

21. Jitsuchon-S R-K. Thailand's poverty maps: from construction to application. In: Bedi TC-A, Simler K, eds. More than a Pretty Picture: Using Poverty Maps to Design Better Policies and Interventions. Washington, DC: The World Bank, 2007.

22. Spiegel JM, et al. Social and environmental determinants of Aedes aegypti infestation in Central Havana: results of a case-control study nested in an integrated dengue surveillance programme in Cuba. Tropical Medicine and International Health 2007; 12: 503-510.

23. Mondini A, Chiaravalloti-Neto F. Spatial correlation of incidence of dengue with socioeconomic, demographic and environmental variables in a Brazilian city. Science of the Total Environment 2008; 393: 241-248.

24. Thammapalo S, et al. Environmental factors and incidence of dengue fever and dengue haemorrhagic fever in an urban area, Southern Thailand. Epidemiology and Infection 2008; 136: 135-143.

25. Nagao Y, et al. Geographical structure of dengue transmission and its determinants in Thailand. Epidemiology and Infection 2008; 136: 843-851.

26. Chang LH, et al. Differential survival of Aedes aegypti and Aedes albopictus (Diptera: Culicidae) larvae exposed to low temperatures in Taiwan. Journal of Medical Entomology 2007; 44: 205-210.

27. Watts DM, et al. Effect of temperature on the vector efficiency of Aedes aegypti for dengue 2 virus. American Journal of Tropical Medicine and Hygiene 1987; 36: 143-152.

28. Juliano SA, et al. Desiccation and thermal tolerance of eggs and the coexistence of competing mosquitoes. Oecologia 2002; 130: 458-469.

29. Yang HM, et al. Assessing the effects of temperature on the population of Aedes aegypti, the vector of dengue. Epidemiology and Infection 2009; 137: 11881202.

30. Alto BW, Juliano SA. Precipitation and temperature effects on populations of Aedes albopictus (Diptera: Culicidae): implications for range expansion. Journal of Medical Entomology 2001; 38: 646-656.

31. University Corporation for Atmospheric Research. (http://dss.ucar.edu/datasets/ds512.0/docs/format_ molynew.html). Accessed 2010.

32. Penman HL. Natural evaporation from open water, hare soil and grass. Proceedings of the Royal Society of London, Series A 1948; 193: 120-145.

33. Monteith JL. Evaporation and environment. Symposia of the Society for Experimental Biology 1965; 19: 205-234.

34. University Corporation for Atmospheric Research. Climate prediction center global summary of day/ month observations (http://dss.ucar.edu/datasets/ ds512.0/). Accessed 2010.

35. Anselin L, Hudak S. Spatial econometrics in practice. A review of software options. Regional Science and Urban Economics 1992; 22: 509-536.

36. Ooi EE, et al. Dengue seroepidemiology in Singapore. Lancet 2001; 357: 685-686.

37. Mammen MP, et al. Spatial and temporal clustering of dengue virus transmission in Thai villages. PLoS Medicine 2008; 5: e205.

38. Kan CC, et al. Two clustering diffusion patterns identified from the 2001-2003 dengue epidemic, Kaohsiung, Taiwan. American Journal of Tropical Medicine and Hygiene 2008; 79: 344-352.

39. Hu W, et al. Spatial analysis of notified dengue fever infections. Epidemiology and Infection 2011; 139: 391-399.

40. Tsuda Y, et al. Different spatial distribution of Aedes aegypti and Aedes albopictus along an urban-rural gradient and the relating environmental factors examined in three villages in northern Thailand. Journal of the American Mosquito Control Association 2006; 22 : 222-228.

41. Carbajo AE, et al. Dengue transmission risk maps of Argentina. Tropical Medicine and International Health $2001 ; 6:$ 170-183.

42. Jokelainen $\mathbf{P}$, et al. Toxoplasma gondii in wild cervids and sheep in Finland: north-south gradient in seroprevalence. Veterinary Parasitology; 171: 331-336.

43. McKinnon L, et al. Lower predation risk for migratory birds at high latitudes. Science; 327: 326-327.

44. Pontes RJ, et al. Vector densities that potentiate dengue outbreaks in a Brazilian city. American Journal of Tropical Medicine and Hygiene 2000; 62 : 378-383.

45. Cummings DA, et al. Travelling waves in the occurrence of dengue haemorrhagic fever in Thailand. Nature 2004; 427: 344-347.

46. Macdonald G. The analysis of equilibrium in malaria. Tropical Diseases Bulletin 1952; 49: 813-829.

47. Marques CA, Forattini OP, Massad E. The basic reproduction number for dengue fever in Sao Paulo state, Brazil: 1990-1991 epidemic. Transactions of the Royal Society of Tropical Medicine and Hygiene 1994; 88: $58-59$.

48. Ferguson NM, Donnelly CA, Anderson RM. Transmission dynamics and epidemiology of dengue: insights from age-stratified sero-prevalence surveys. Philosophical Transactions of the Royal Society of London, Series B: Biological Sciences 1999; 354: 757-768.

49. Massad E, et al. Estimation of $R_{\mathbf{0}}$ from the initial phase of an outbreak of a vector-borne infection. Tropical Medicine and International Health 2010; 15: 120-126.

50. Sangkawibha N, et al. Risk factors in dengue shock syndrome: a prospective epidemiologic study in Rayong, Thailand. I. The 1980 outbreak. American Journal of Epidemiology 1984; 120: 653-669. 